\title{
An Experimental Study and Numerical Modeling of the Flow in a Network of Triangular Microchannels
}

\author{
MARIUSZ NIKLAS \\ Institute of Thermal Machinery, University of Czestochowa, Poland \\ MICHEL FAVRE-MARINET \\ Laboratoire des Ecoulements Géophysiques et Industriels, Grenoble, France
}

The flow characteristics of a network of parallel microchannels (hydraulic diameter: $110 \mu \mathrm{m}$ ) are investigated both experimentally and numerically. The microchannel cross-section was triangular, as in the case of microheat pipes. The pressure drop across the microchannel network showed a dramatic increase with a departure from the law of fully developed flow in ducts as soon as the Reynolds number of the flow exceeded about 10. Numerical computation of the flow was carried out using the classical laws of hydrodynamics in an attempt to explain this surprising result. There was a good agreement with experimental results, which suggests that there are no size effects at the length scales used in the experiments. Moreover, the mechanisms responsible for the large pressure drop for higher Reynolds numbers were identified in the numerical analysis as being extra head losses due to separation in several parts of the test section.

\section{INTRODUCTION}

\section{Background}

Much work in recent years has gone into the development of microchannel technology. This has been especially useful in electronics where ever faster and smaller microchips are built. Heat removal, however, is a major problem, that limits the capabilities of such circuits. High speeds are accompanied by the intense generation of heat, so the development of higher density and faster microchips requires significant heat removal from these components. This trend in miniaturization requires the development of very small and efficient heat exchangers. As a result, exchangers based on microchannel technology have begun to be used. Enhancement of the heat transfer coefficient is obviously required, along with a reduction in length scales.

This research was supported by the Rhône-Alpes Region. The authors would like to gratefully acknowledge the Socrates program for partly supporting the visit of Mariusz Niklas to Grenoble. They also wish to thank Nicolas Mazellier for performing the experiments.

Address correspondence to Pr. Michel Favre-Marinet, Laboratoire des Ecoulements Géophysiques et Industriels, CNRS-UJF-INPG, 1025 rue de la Piscine, BP 53 X, 38041, Grenoble Cedex, France. E-mail: Michel.FavreMarinet@hmg.inpg.fr
This has been observed many times since the first experiments of Tuckerman and Pease [1]. Li [2] reported that the major advantage of microchannel heat sinks is related to the high heat transfer coefficients, up to sixty times higher than in conventional, macroscale heat exchangers.

Many experimental studies on microchannels are reported in the literature and show that some results cannot be explained by conventional theories of transport phenomena (for a review, see [3-5]). Even if the discussion is restricted to papers related to single phase flows in trapezoidal microchannels, contradictory conclusions appear regarding the flow hydrodynamics. Wu and Little [6-7] investigated flows in microchannels of a trapezoidal cross-section (hydraulic diameter between 45.5 to $83.1 \mu \mathrm{m}$ ) etched in a silicon substrate and abraded into glass. They measured friction factors larger than predicted on the basis of conventional laws for circular pipes. Urbanek et al. [8] observed a temperature dependence of the Poiseuille number in triangular and trapezoidal microchannels. Flockhart and Dhariwal [9] found no scale effects on the hydraulics in trapezoidal channels etched in silicon wafers (27 or 63 microns in height, Reynolds number <240). However, Qu et al. [10] observed a significant increase in the friction factor $f$ in the same type of channels (height 28 to 111 microns) over the whole range of Re investigated (up to 1600). 
A discussion of the possible microscale effects can be found in Mala et al. [11], Guo and Li [4], and Koo and Kleinstreuer [12]. These analyses took into account the effects due to channel entrance, wall slip, surface roughness, electrokinetics, and variable fluid properties. At the moment, there is no agreement concerning the phenomena involved in the physics of these flows. It is therefore necessary to carry out a number of fundamental studies to identify the differences between experimental data and conventional flow characteristics and to detect at which length scale such differences appear.

\section{Motivation of the Present Work}

This study forms part of a joint project involving several laboratories, with the goal of designing new heat pipes of a very small size (typical length scale of $200 \mu \mathrm{m}$ ). Since hydrodynamics, and in particular the resisting wall friction, play an important role in the working principles of heat pipes, it was decided to investigate single-phase isothermal flows across microchannels of triangular cross-section identical to those that will be used for heat pipe operation. The present study concerns flows across a network of 55 parallel microchannels [13]. Experiments were conducted on a test section identical to the microheat pipe prototype, except that the network was connected to an external closed-loop circuit. Measurements of the pressure drop across the network as a function of the flow rate were complemented by a numerical computation of the flow in order to interpret the data and detect possible size effects on the results.

Another issue of this study is the distribution of the flow rate and pressure losses in a network of parallel microchannels as is relevant to the problems of microheat exchangers. Hetsroni et al. [14] recently investigated a system of parallel microchannels etched in a silicon substrate. The cross-section of each channel was an isosceles triangle with a base of 200$310 \mu \mathrm{m}$. Experiments were performed with air-water and steamwater two-phase flows. Adiabatic single-phase flows were studied by Yin et al. [15] in parallel microchannels with a working fluid of nitrogen. Each microchannel had a round cross-section $0.787 \mathrm{~mm}$ in diameter. The authors linked the pressure measurements with conventional published correlations on head losses to analyze the total pressure drop across a microchannel heat exchanger. This approach enabled them to identify and quantify internal manufacturing defects. In the present study, we consider single-phase flows in parallel triangular microchannels, $110 \mu \mathrm{m}$ in hydraulic diameter. To our knowledge, there is no published work on single-phase flows of such small size in this geometric configuration.

\section{EXPERIMENTAL SETUP}

\section{Geometry of the Test Section}

The main element of the experimental setup was a cell consisting of two silicon wafers bonded together. One of the wafers

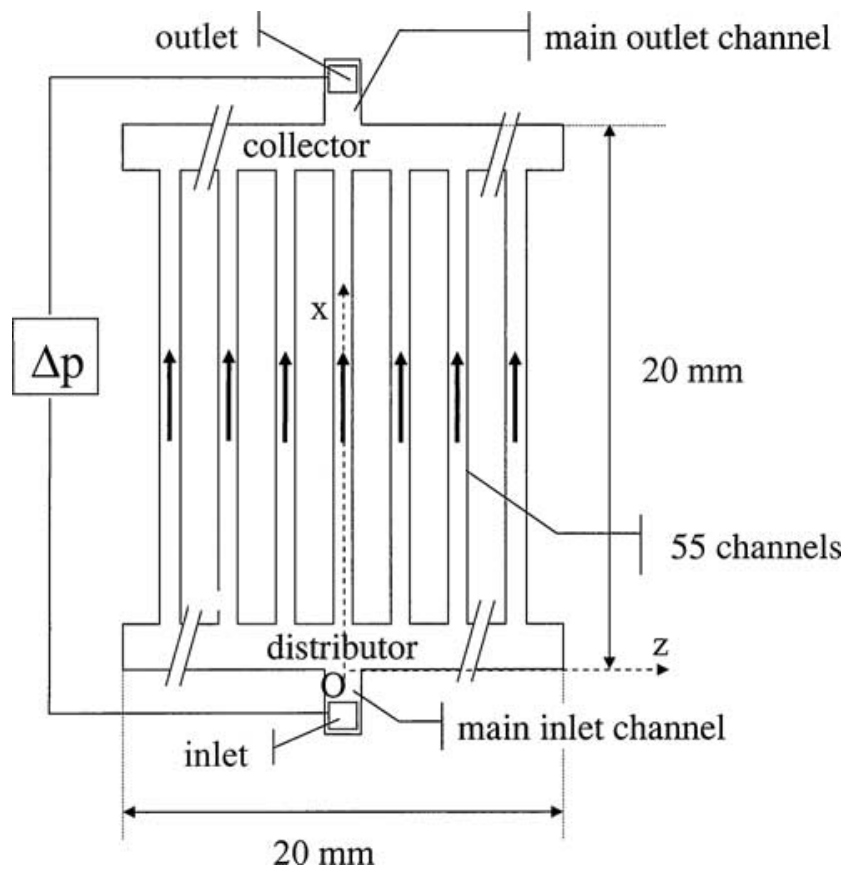

(a)

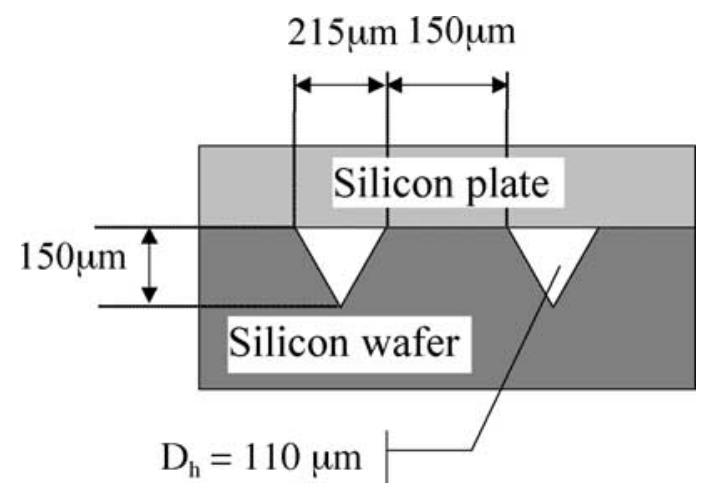

(b)

Figure 1 System of parallel triangular channels on the silicon plate: a) top view, b) cross-sectional view.

was etched via a wet anisotropic technique to form a system of 55 parallel microchannels of triangular cross-section. The configuration of the channels network is depicted in Figure 1; the dimensions are given in Table 1 . The channels were $215 \mu \mathrm{m}$ in

Table 1 Geometric parameters of the cell

\begin{tabular}{lll}
\hline Triangular microchannels & Microchannel width & $215 \mu \mathrm{m} \pm 10 \mu \mathrm{m}$ \\
& Microchannel height & $150 \mu \mathrm{m} \pm 5 \mu \mathrm{m}$ \\
& Hydraulic diameter & $\mathrm{D}_{\mathrm{h}}=110 \mu \mathrm{m}$ \\
& Microchannel length & $\mathrm{L}=18.4 \mathrm{~mm}$ \\
Distributor channel & Channel height & $\mathrm{h}_{\mathrm{dc}}=188 \mu \mathrm{m}$ \\
Collector channel & Channel width & $\mathrm{a}_{\mathrm{dc}}=800 \mu \mathrm{m}$ \\
& Channel length & $\mathrm{L}_{\mathrm{dc}}=20 \mathrm{~mm}$ \\
Main inlet and outlet channels & Channel height & $\mathrm{h}_{\mathrm{io}}=188 \mu \mathrm{m}$ \\
& Channel width & $\mathrm{a}_{\mathrm{io}}=835 \mu \mathrm{m}$ \\
& Channel length & $\mathrm{L}_{\mathrm{io}}=1.5 \mathrm{~mm}$ \\
\hline
\end{tabular}


width and $150 \mu \mathrm{m}$ in height, which gives a hydraulic diameter of $\mathrm{D}_{\mathrm{h}}=110 \mu \mathrm{m}$. The length $(\mathrm{L}=18.4 \mathrm{~mm})$ corresponds to very long channels $\left(\mathrm{L} / \mathrm{D}_{\mathrm{h}}=167\right)$. All of the channels were connected to an upstream distributor channel, called the header and a downstream collector channel of identical rectangular cross-section (width $800 \mu \mathrm{m}$, height $188 \mu \mathrm{m}$ ). The system was covered with a second silicon wafer fixed by direct wafer bonding. Two holes $\left(1.5 \times 1.5 \mathrm{~mm}^{2}\right)$ were made in the cover in order to connect the network of microchannels to a demineralized water circuit. They were located in the plane of symmetry of the test section. The surface area of the channel network was equal to $2 \times 2 \mathrm{~cm}^{2}$. The cell was inserted and maintained tightly between two large blocks fastened with bolts. Large diameter holes were tapped into one of the blocks to connect the cell to the external loop. Tee-shaped connectors (internal diameter $=3 \mathrm{~mm}$ ) were then screwed onto the block and used to take pressure measurements. Since the cross-section of the connecting parts of the system was much larger than the cell channel dimensions (47 times the collector/distributor cross-section), it was assumed that the pressure at the connector taps was the same as at the inlet/outlet cell ports.

The $\mathrm{x}$-direction runs along the axis of symmetry of the system and the z-axis across the distribution channel. The origin is at the distribution channel inlet on the axis of symmetry of the system (see Figure 1).

The Reynolds number of the flow is based on the average bulk velocity $\mathrm{V}$ across the channels (flow rate/total cross-sectional area) and the hydraulic diameter $\mathrm{D}_{\mathrm{h}}$ of one channel. The range of Reynolds number investigated was 1 to 700 . The pressure drop $\Delta \mathrm{p}$ across the complete system of channels is related to the Fanning friction factor $f$ via

$$
f=\frac{\Delta \mathrm{p}}{2 \rho \mathrm{V}^{2}} \frac{\mathrm{D}_{\mathrm{h}}}{\mathrm{L}}
$$

The Poiseuille number is defined as

$$
\mathrm{Po}=f \operatorname{Re}
$$

\section{Instrumentation}

The pressure drop $\Delta \mathrm{p}$ was measured either using piezoresistive strain gauge transmitters placed upstream and downstream of the cell (full scale, $10^{6} \mathrm{~Pa}$; accuracy, $10^{4} \mathrm{~Pa}$ ) or a differential gauge (full scale, $10^{4} \mathrm{~Pa}$; accuracy, $10^{2} \mathrm{~Pa}$ ). The flow rate was measured by precision weighing or using a highaccuracy flowmeter (full scale, $0.251 \mathrm{~min}^{-1}$; accuracy, 0.0011 $\min ^{-1}$ ) for the highest flow rates. The main uncertainties in the measurements are due to the determination of the microchannel dimensions, which play a crucial role in the pressure losses. The dimensions were measured by a mechanical profilometer. Uncertainties are given in Table 1.

\section{NUMERICAL COMPUTATIONS}

\section{Numerical Scheme}

Numerical computations of the flow were carried out by using the commercial code Fluent 5.4. The flow regime was assumed to be laminar. Continuity and Navier-Stokes equations were discretized by means of a second-order upwinding finite volume method. As these equations are non-linear, a SIMPLEC (SemiImplicit Pressure-Linked Equations-Consistent) algorithm was used. This algorithm is based on a prediction-correction method that allows the equations to be linearized and solved iteratively. The pressure under-relaxation factor was set to one. Meshing was performed by using Gambit 1.3 . Boundary conditions consisted of a no-slip condition at the walls and a fixed pressure at the domain outlet. The mesh was unstructured in the crosssection of the microchannels (triangular cells) and structured in the longitudinal direction (rectangular cells). It was unstructured in the other parts of the flow. Several cases were computed by varying the flow rate across the system. The solution was treated as converged when the residual level was lower than $10^{-5}$. The evolution of the pressure drop as a function of the number of iterations was also checked.

\section{Numerical Accuracy}

Preliminary tests on accuracy were performed during the computations of a single channel flow with periodic conditions, which corresponds to fully developed flow in the channel. During these tests, the cells were equally distributed along the channel. Convergence was obtained after approximately 1000 iterations (level of normalized residuals less than $10^{-5}$ ). Grid influence was tested on the calculated pressure drop across a single channel. It was observed that about 200 cells in the crosswise direction are sufficient to have a satisfactory result, the asymptotic value being approached to within an accuracy of $0.5 \%$ with this number of cells. As a result, 214 cells were used in further computations. The mesh was refined near the inlet in the streamwise direction to compute the developing boundary layers. It was then checked that the pressure drop was independent of the number of cells along the channel when more than thirteen cells were considered. For the complete system, the mesh consisted of about 600,000 prism/wedge elements. Grid independence was carefully checked on the solution. Comparisons showed that small differences (less than 3\%) were obtained for 300,000, 600,000, and 900,000 elements.

\section{RESULTS}

Figure 2 shows the experimental results. Uncertainties on Po and Re were estimated by standard methods [16] from precision errors on the various parameters and are reported on the graph. 


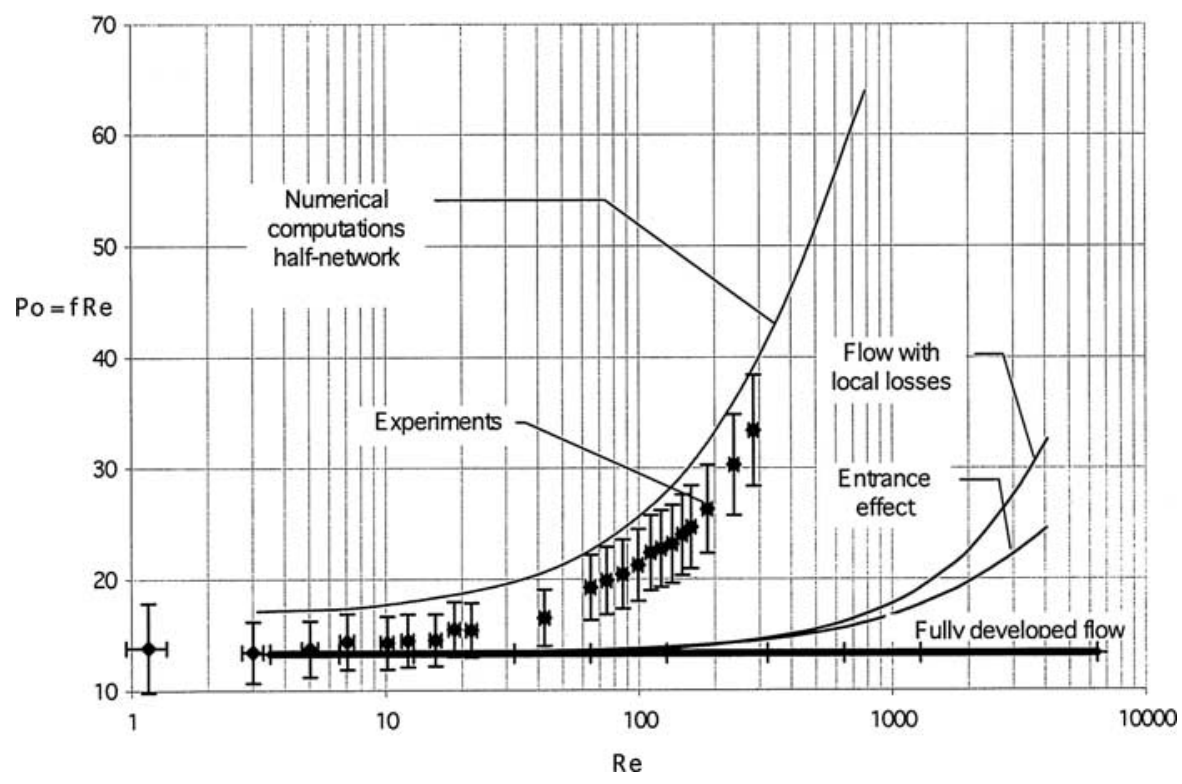

Figure 2 Pressure drop across the system of microchannels.

Precision errors on the microchannel dimensions accounted for the largest contribution to these uncertainties. The other data plotted in Figure 2 correspond to numerical results and will be detailed later. The experimental pressure drop deviates from the theoretical result for fully developed flow in triangular channels at low values of the Reynolds number (between 10 and 20). This deviation corresponds to between eight and sixteen dimensionless channel lengths $\mathrm{L}^{+}\left(=\mathrm{L} / \mathrm{D}_{\mathrm{h}} 1 / \mathrm{Re}\right)$, which is much larger than expected in duct flows $(\approx 0.1)$. However, it must be noted that the measured pressure drop corresponds to the whole system, including the triangular microchannels. The aim of the following section is to indicate the contribution of the various parts of the system to the total pressure drop, deduced from numerical computations.

\section{Single Channel Flow}

Preliminary calculations were divided into three steps for a single triangular microchannel. These were:

1. fully developed flow in a channel

2. flow with entrance effects due to the development of boundary layers

3. flow with local losses due to a sudden change in the crosssectional area at the inlet of a microchannel.

Streamwise-periodic conditions over the microchannel length were assumed for the velocity field for the first step. The computations of the fully developed flow provided excellent agreement with the results of the literature $(\mathrm{Po}=13.3$ [17]). The velocity was assumed uniform at the channel inlet, and the development of boundary layers was computed for the second step. The final step considered a channel of rectangular cross-section (height $188 \mu \mathrm{m}$, width $215 \mu \mathrm{m}$ ) followed by a microchannel with a triangular cross-section of the same maximal width. For the two latter cases, the grid was carefully refined near the microchannel inlet, where the boundary layers are developing.

Figure 2 compares the numerical results to the experimental data. It clearly shows that the entrance effects in the microchannels have little influence on the flow resistance and cannot account for the rapid rise in pressure drop when the Reynolds number grows beyond about twenty.

\section{Flow Through the System of Microchannels}

In the next phase of the work, the computational domain was similar to the real network of channels but was reduced to onehalf of the whole system owing to the symmetry of the flow (see Figure 3). The inlet condition was simplified in comparison with the actual arrangement, which corresponds to a flow inlet perpendicular to the cell plane. It was modeled as a uniform velocity distribution at the entrance of a small channel of rectangular cross-section, denoted as the main inlet channel in Figure 1. A symmetrical outlet channel was considered at the flow exit (Figure 1 and Table 1). A condition of symmetry in the mid-plane of the cell was used in the computations.

\section{Pressure Losses}

When the complete model is considered, the numerical results closely follow the tendency of the experimental data (see Figure 2). The pressure drop across the system is slightly overestimated by the computations. These differences may be due to uncertainties in the numerical simulations and the simplification of the actual inlet/outlet system. There are also possible additional errors in the measurements due to, for example, the 


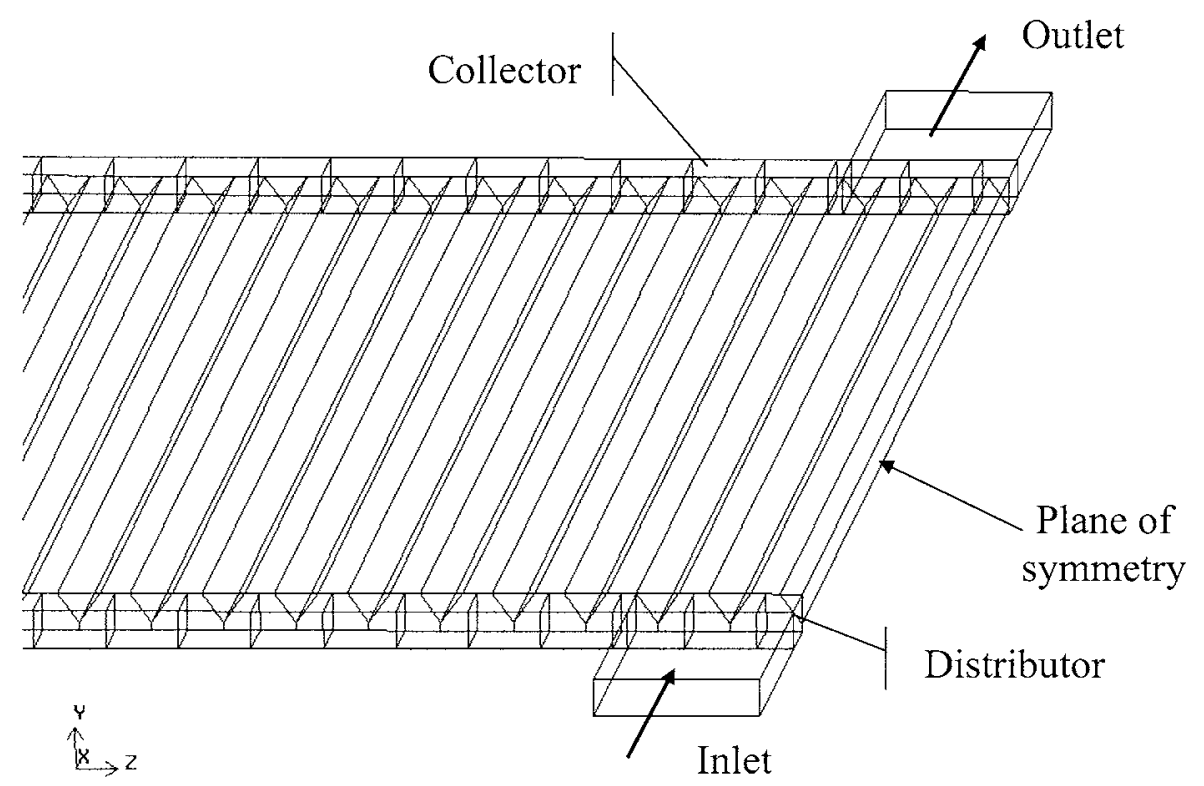

Figure 3 Computational domain of the complete model.

presence of air trapped in the corners of the triangular crosssection, something that cannot be completely excluded. Guo and $\mathrm{Li}$ [4] suggested that this phenomenon could give rise to a reduction in the actual cross-section and to subsequent local acceleration of the flow. They also claimed that the reduction of the wetted area should be the prevailing phenomenon, giving rise to a reduction in the measured friction factor. This could partly account for the differences between the present experimental and numerical results. On the other hand, specific small size effects were discussed by Koo and Kleinstreuer [12]. These authors indicate that among possible microscale effects, the wall slip velocity is negligible for liquid flows in microchannels, though this effect can probably be discarded in the present case.

Figure 4 shows the contribution of the various phenomena to the total pressure losses as a function of the Reynolds number. In this figure, the different sources of pressure losses in

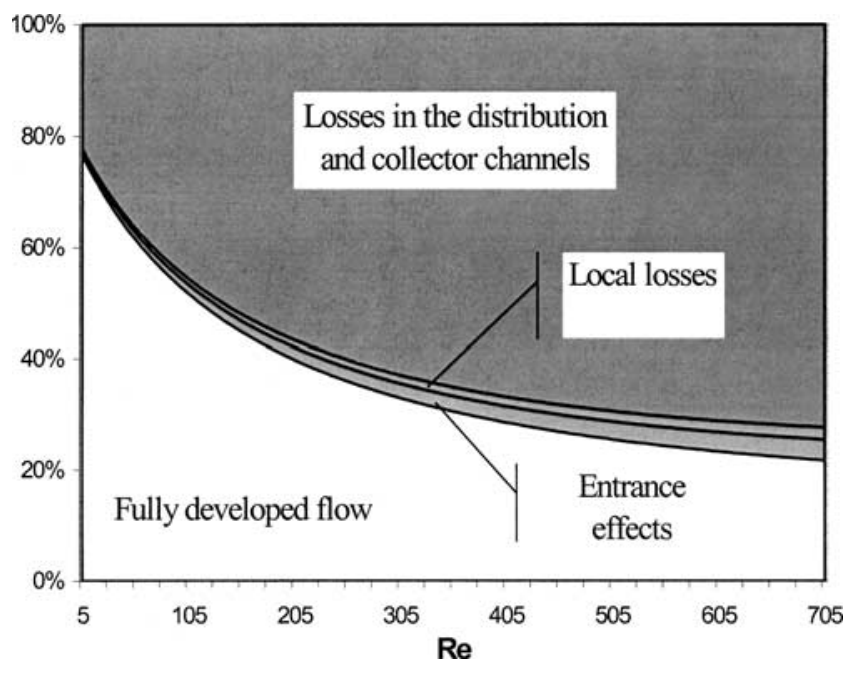

Figure 4 Contribution to total pressure losses versus Re number. the flow are separated. The curves correspond to the various assumptions used for the computations and reproduce the results associated with each assumption. The bottom part of the figure corresponds to a fully developed flow along the entire length of the microchannels. Additional losses due to entrance effects and losses associated with the sudden change of the cross-sectional area at the beginning of the microchannels correspond to the next two regions. Finally, the upper part of the figure corresponds to the sum of the pressure losses in the main inlet/outlet channels and in the distributor/collector. This figure demonstrates that two main phenomena have a significant contribution to the total losses in the system. The regular losses in the microchannels account for a very large part of the total losses at low values of the Reynolds number $(80 \%$ for $\mathrm{Re}=5$ ). This contribution obviously decreases when the Reynolds number is increased ( $20 \%$ for $\mathrm{Re}=700$ ). This may be understood since the regular pressure drop in a microchannel is proportional to the flow rate whereas the pressure losses in the other parts of the system are due to separation and mixing, as presented hereafter, and are likely to be proportional to the flow rate squared. This latter scaling law is confirmed by Figure 5, which shows the difference between the actual value of the Poiseuille number and the value $\left(\mathrm{Po}_{\text {viscous }}\right)$ reached for very low values of the Reynolds number. Logarithmic scales are used to highlight the Re-dependence of the modified Poiseuille number Po - $\mathrm{Po}_{\text {viscous }}$. Figure 5 clearly demonstrates the linear dependence of Po $-\mathrm{Po}_{\text {viscous }}$ versus $\mathrm{Re}$ for large values of this parameter. The corresponding pressure losses are therefore characterized by a constant friction factor (Eq. 2).

As can be seen in Figure 4, the pressure drop is caused mainly by losses in the distributor and collector channels for the high range of Reynolds numbers. For Re higher than 200, the pressure drop caused by friction in the microchannels is less than half of the total losses. 


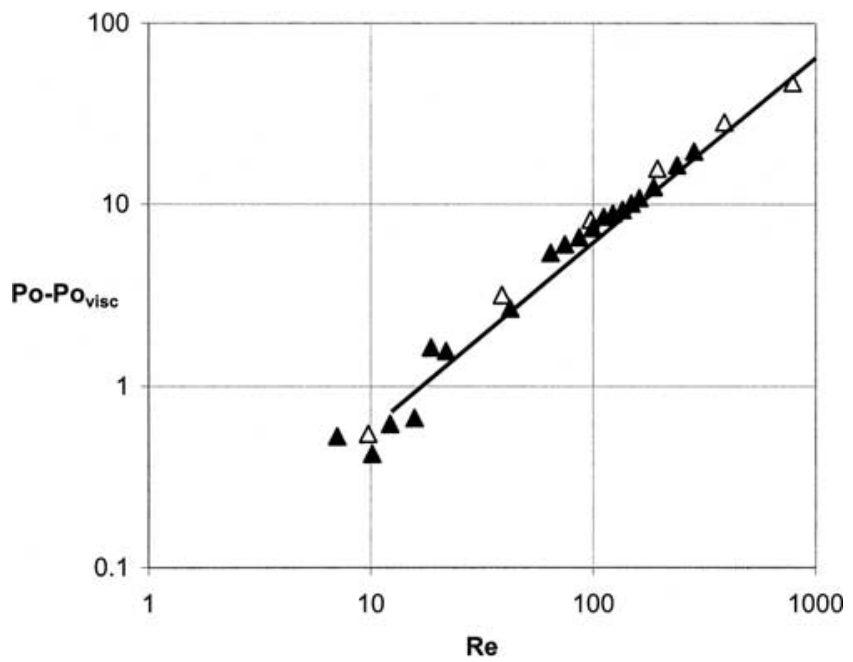

Figure 5 Modified pressure drop across the system of microchannels: $\boldsymbol{\Delta}$ experimental results, $\triangle$ numerical results.

Due to the good agreement between the present numerical and experimental results, it may be concluded that the deviation of Po from the fully-developed solution in long channels in the laminar regime is due to inertial pressure losses in the distributor and the collector channels. It is worth recalling that the present numerical computations were based on the assumption that the fluid is a continuum and on the classical laws of hydrodynamics, which predict the flow reasonably well. It seems therefore that no size effects are present in the flow investigated, which was characterized by a length scale of $110 \mu \mathrm{m}$. The same conclusion was found by Gao et al. [18] for flows in two-dimensional microchannels $100 \mu \mathrm{m}$ in height.

\section{Pressure and Velocity Fields}

Further insight into the flow may be gained from analysis of the pressure and velocity fields deduced from the numerical results. For the following presentation of results, the pressure and velocity fields are considered in the plane located at $y=100 \mu \mathrm{m}$ above the bottom of the microchannels. The pressure field is illustrated on Figures 6-8 for one typical value of the Reynolds number $(\operatorname{Re}=390)$. The pressure is normalized in

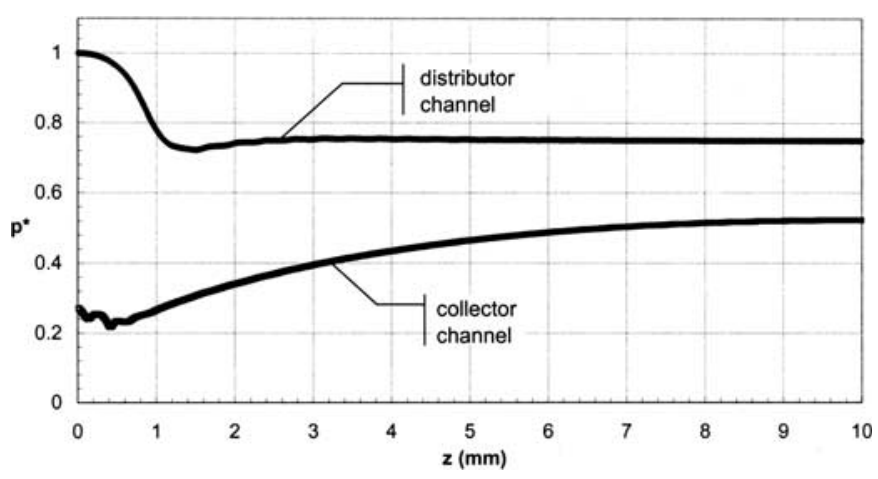

Figure 6 Pressure along the distributor and collector channels for $\mathrm{Re}=390$ Pressure is given in the planes of symmetry parallel to Oz-axis of both channels.

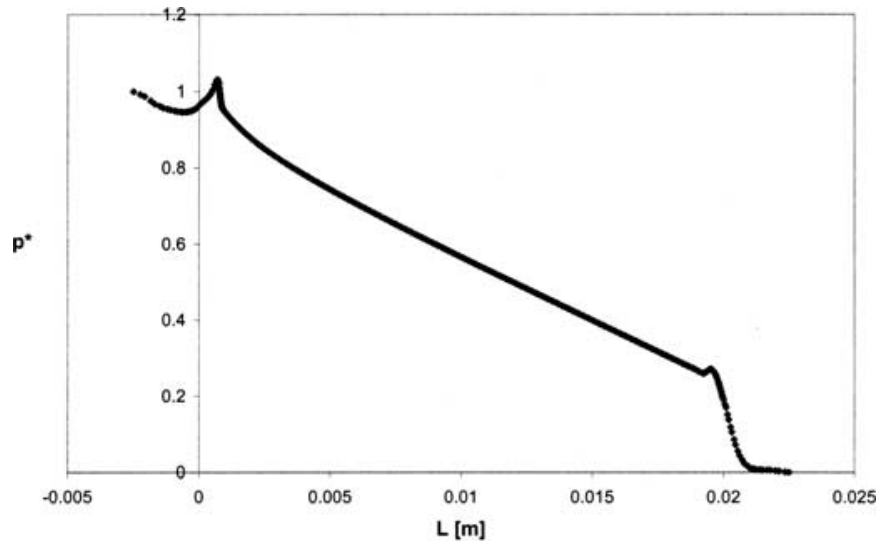

Figure 7 Pressure on the center line across the system of channels for $\operatorname{Re}=390$.

Figures 6 and 7 by

$$
\mathrm{p}^{*}=\frac{\mathrm{p}-\mathrm{p}_{\text {ref }}}{\mathrm{p}_{\max }-\mathrm{p}_{\text {ref }}}
$$

where $\mathrm{p}_{\max }$ is the pressure at the distributor channel inlet and $\mathrm{p}_{\text {ref }}$ is the pressure at the exit section of the main outlet channel $\left(\mathrm{p}_{\text {ref }}=101,000 \mathrm{~Pa}\right)$.

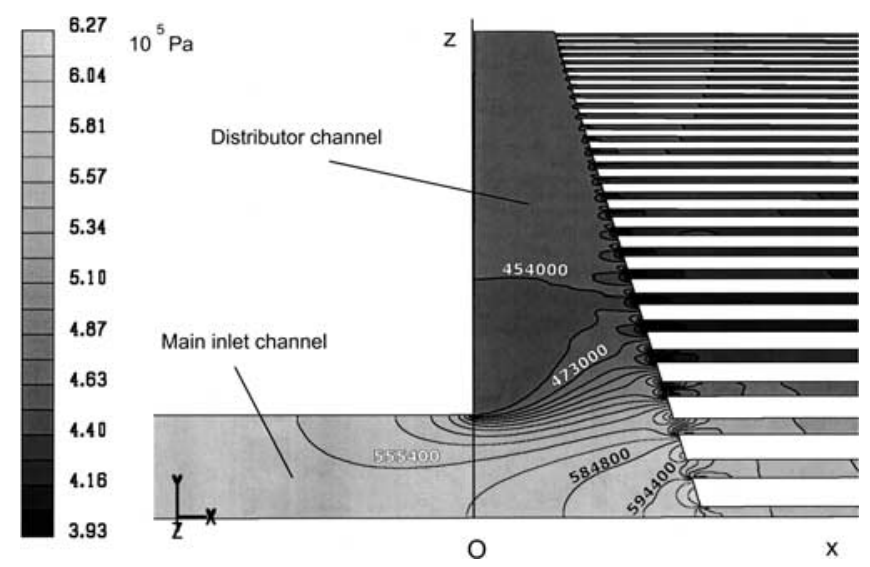

(a)

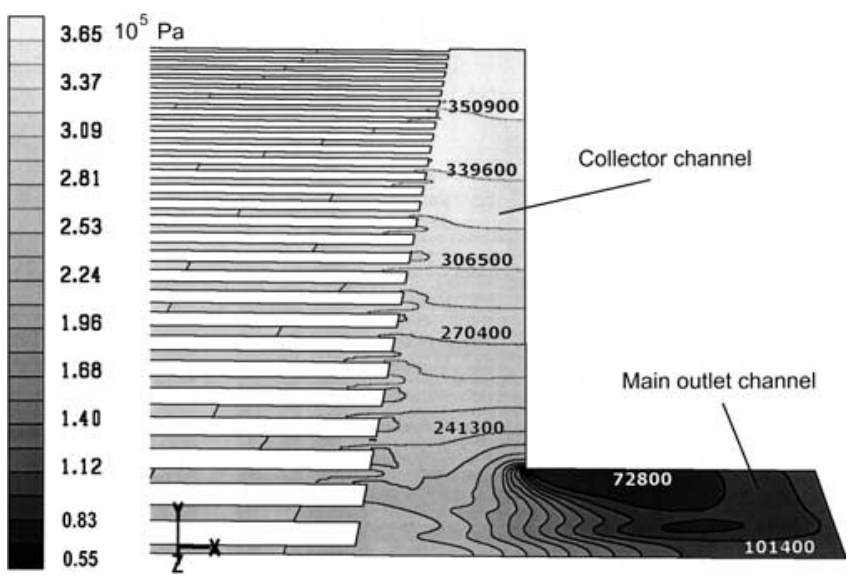

(b)

Figure 8 Contours of static pressure for $\operatorname{Re}=390$ : a) in the inlet region, b) in the outlet region. 
The normalized pressure exhibits a sharp drop near the inlet of the distribution channel and only slight variations further downstream (see Figure 6). The variations of $\mathrm{p}^{*}$ are more uniformly distributed along the collector channel. These results may be compared to those of Yin et al. [15], who measured the pressure drop in a microchannel heat exchanger. Their heat exchanger consisted of 41 tubes, each tube having eleven ports $0.787 \mathrm{~mm}$ in diameter. Contrary to the present arrangement, the inlet and outlet were placed at opposite sides of the distributor and collector channels. Despite this difference, the trend for the pressure drop is the same in both studies. Yin et al. [15] found that the pressure drop in the exit header was much higher than that in the inlet header. Figure 6 shows that the pressure variation is also much higher in the collector channel than that in the distributor channel if we exclude the strong pressure drop over the first $\mathrm{mm}$ of this channel. These larger pressure losses may be due to jet mixing in the collector channel, as discussed later. Figure 7 shows the pressure variations along the axis of symmetry of the system. The left part of the curve corresponds to the main inlet channel $(\mathrm{x}<0 \mathrm{~mm})$ and the distribution channel. The triangular microchannel starts at $\mathrm{x}=0.8 \mathrm{~mm}$ and ends at $\mathrm{x}=19.2 \mathrm{~mm}$. The collector channel and the main outlet channel correspond to $x>19.2 \mathrm{~mm}$ symmetrically from the inlet part. The linear pressure distribution from $\mathrm{x}=0.8 \mathrm{~mm}$ to $\mathrm{x}=19.2 \mathrm{~mm}$ shows a regular pressure drop along the microchannel located in the plane of symmetry.

The distribution of bulk velocities in the system of parallel microchannels is plotted in Figure 9. The results of the computations were completed using symmetry to depict the complete system. The mean velocities vary significantly from channel to channel according to the pressure differences shown in Figure 6. The highest velocities and mass flow rates are observed near the axis of symmetry of the system of channels, as expected. It is worth noting that the ratio of the highest to lowest bulk velocities along the system is slightly Reynolds-dependent (equal to 2.5 for $\operatorname{Re}=195$ and 3 for $\operatorname{Re}=390$ ). This maldistribution of the total flow rate is associated with the present arrangement of the flow inlet and outlet. It should be noted that the objective of the research was to investigate the flow characteristics of a test section with the same geometry as that of a microheat pipe. A better arrangement from the point of view of microheat exchangers would probably have been obtained by placing the inlet and outlet at opposite sides of the distributor and collector channels. Preliminary computations of this arrangement confirm this tendency. Yin et al. [15] also investigated this configuration and found a significantly smaller mass flow maldistribution.

The explanation of the pressure distribution of Figures 6 and 8 is clearly visible in Figure 10, which shows contours of the $\mathrm{z}$-velocity component in the inlet region. Figure $10 \mathrm{~b}$ shows these contours over several cross-sections of the distributor channel. The z-direction is perpendicular the axis of symmetry of the system so that Figure 10 shows the flow along the distributor channel. The sudden change in the flow direction at the end of the main inlet channel gives rise to a strong separation at the beginning of the distribution channel. This reverse flow causes a significant reduction of the distribution channel cross-section and consequently to a high pressure drop in this region (see Figure 6). Low pressures are associated with the region of separation (see Figure 8a). Sufficiently far from the region of reversed flow, the pressure is practically constant.

Figure 11 shows the contours of the $\mathrm{x}$-velocity component in the outlet region. The $\mathrm{x}$-axis corresponds to the outlet channel direction. The flow pattern in the collector channel is quite different from that in the distributor channel. This region is dominated by the merging of jets exiting the triangular microchannels. These jets are responsible for flow mixing in the collector channel and for significant head losses in this region. These head losses cannot be easily avoided because they are related to the

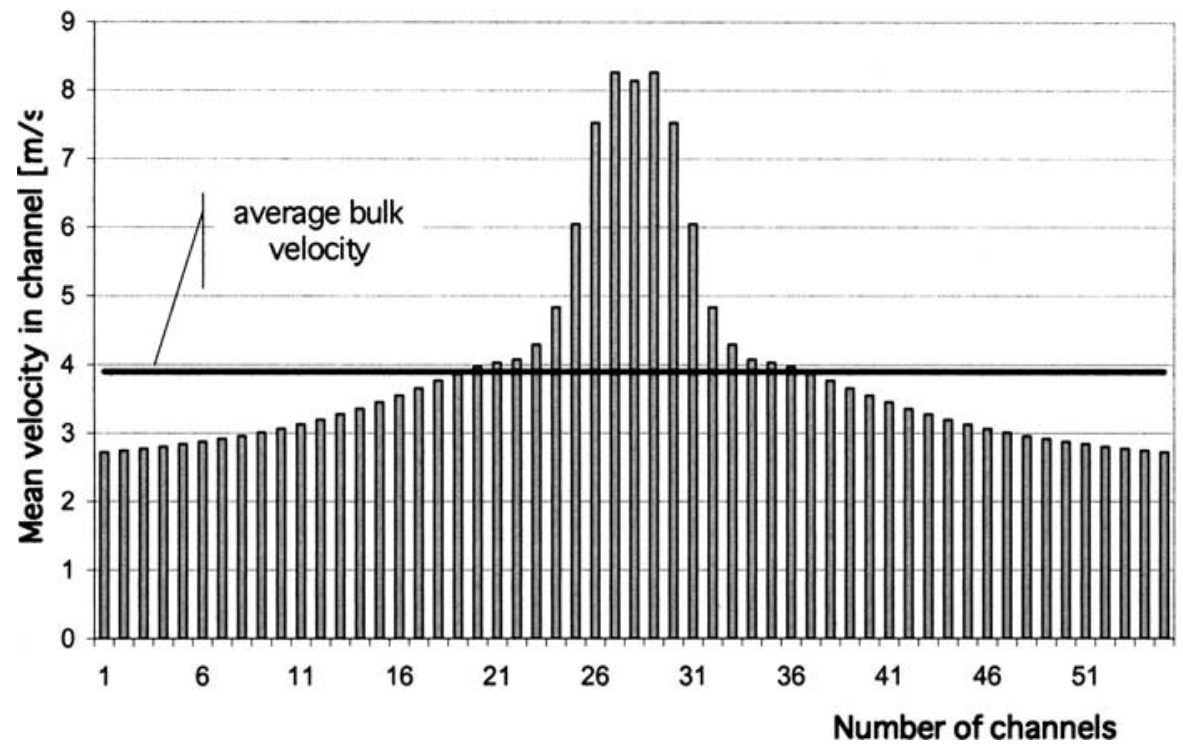

Figure 9 Distribution of bulk velocities in the system of microchannels for $\operatorname{Re}=390$. 

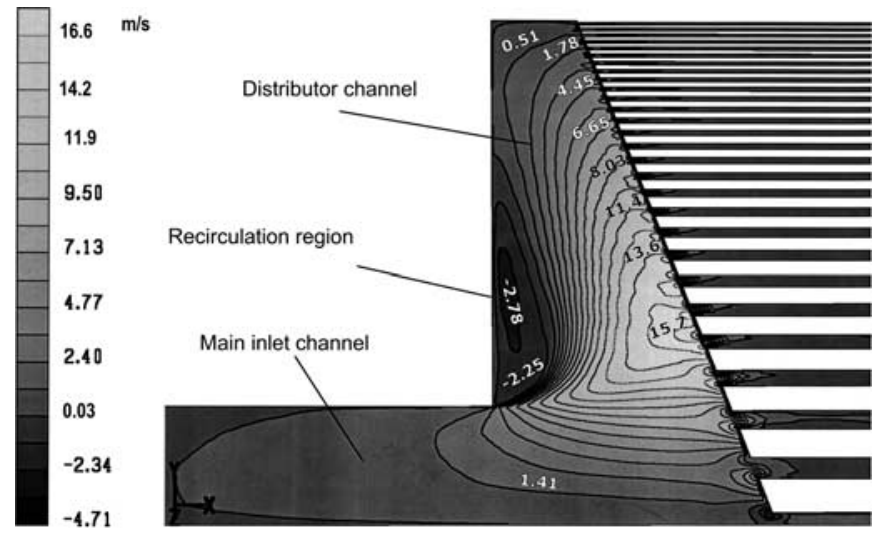

(a)

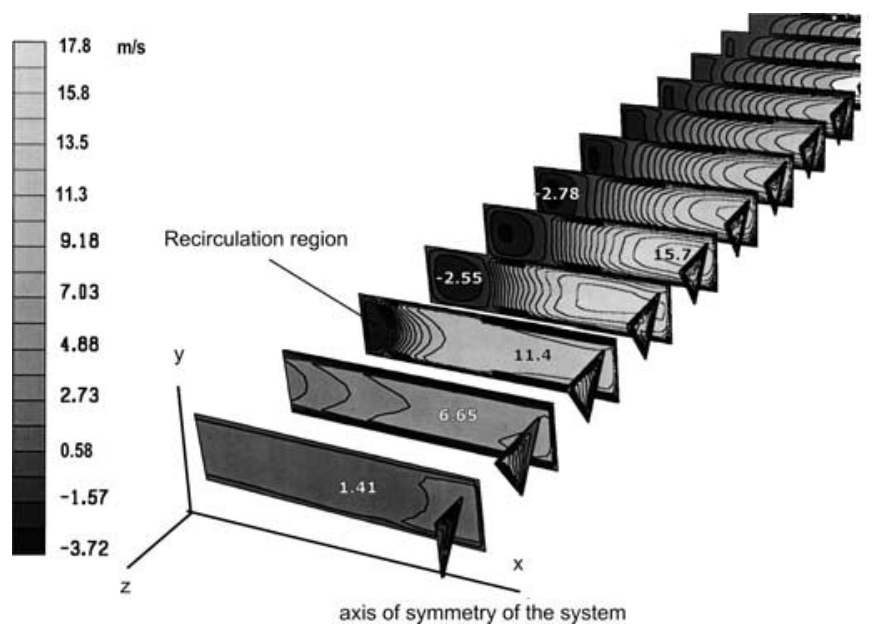

(b)

Figure 10 Contours of $z$ velocity component for $\operatorname{Re}=390$ : a) in the inlet region, b) in cross-sections of the distributor channel.

sudden change of the section at the end of the triangular microchannels (Figure 11, left). Again, a region of separation is found at the beginning of the main outlet channel (Figure 11, right). This is a source of additional pressure losses. The pressure reaches low values in the recirculation region (see Figure 8b),
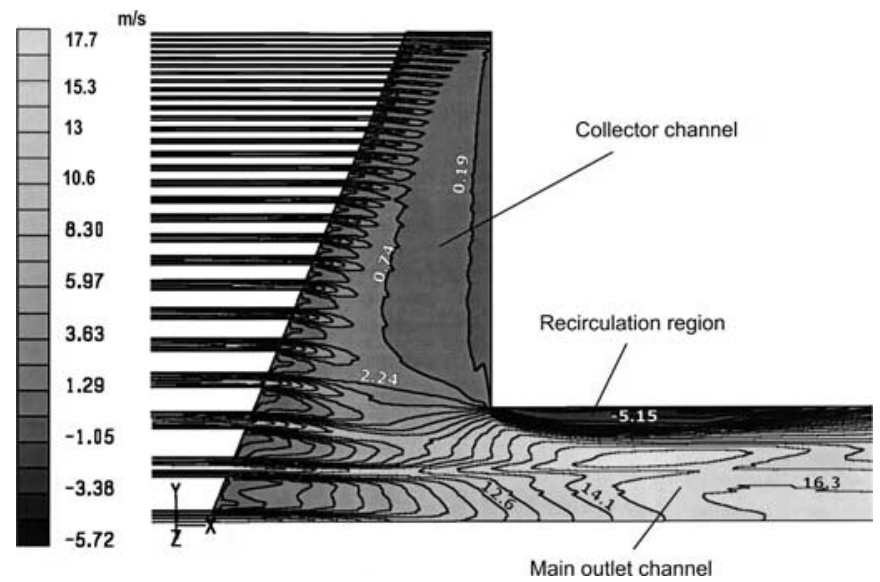

Figure 11 Contours of $\mathrm{x}$ velocity component in the outflow region for $\mathrm{Re}=$ 390.

but they are far from the saturation pressure so that cavitation effects are not expected for this value of Re. However, cavitation cannot be completely excluded for the highest flow rates.

\section{CONCLUSIONS}

The main purpose of the present study was to separate geometric effects from possible scale effects on hydrodynamics in microchannels. Experimental results on the pressure losses across a network of triangular microchannels $110 \mu \mathrm{m}$ in hydraulic diameter were compared to numerical computations based upon the classical laws of hydraulics. The numerical computations were performed in two steps. In the first, the flow was computed in a single channel where fully developed flow, entrance effects due to the development of boundary layers, and local losses due to a sudden change of section were treated. In the second part of the work, the flow was computed for the entire system of channels corresponding to the experiments.

The main conclusion is that no scale effects are observed in the tested system of channels for the size used in the experiments (hydraulic diameter $=110 \mu \mathrm{m}$ ). Numerical computations show that geometric effects are responsible for the deviation from the fully-developed solution in long channels. An analysis of the results shows that the additional pressure losses are mainly due to the following sources:

1. in the collector channel, the pressure losses are caused by the jets issuing from the microchannels. They cannot be avoided because it is impossible to end the microchannels by slow diverging sections owing to the lack of space between two consecutive channels.

2. separation is present in the inlet region and the main outlet channel. The passage from the main inlet channel to the distribution channel should be appropriately profiled to avoid separation. The same can be said for the outlet channel.

This research also underlines the care that must be taken in interpreting pressure measurements during the study of microchannel flows. An estimation of the pressure drop across one microchannel requires a careful separation of pressure variations in the region of interest and in the parts of the system used to connect the microchannel to an external hydraulic circuit.

Finally, it should also be stressed that the careful design of a complex network of microchannels is necessary to avoid excessive pressure losses in the system.

\section{NOMENCLATURE}

$\mathrm{D}_{\mathrm{h}}$

$f$

L

$\mathrm{p}$ hydraulic diameter, $\mathrm{m}$

Fanning friction factor (Eq.1), dimensionless microchannel length, $\mathrm{m}$ pressure, $\mathrm{Pa}$ normalized pressure, dimensionless Poiseuille number $(=f R e)$, dimensionless 
$\mathrm{Po}_{\text {viscous }}$ limit of Po when $\mathrm{Re} \rightarrow 0$, dimensionless

$\operatorname{Re} \quad$ Reynolds number $\left(=\frac{\rho \mathrm{VD}_{\mathrm{h}}}{\mu}\right)$, dimensionless

$\mathrm{V}$ average bulk velocity, $\mathrm{m} . \mathrm{s}^{-1}$

\section{Greek Symbols}

$\Delta \mathrm{p} \quad$ pressure drop, $\mathrm{Pa}$

$\mu \quad$ dynamic viscosity, $\mathrm{kg} \cdot \mathrm{m}^{-1} \cdot \mathrm{s}^{-1}$

$\rho \quad$ density, $\mathrm{m}^{3} \cdot \mathrm{s}^{-1}$

\section{REFERENCES}

[1] Tuckerman, D. B., and Pease, R. F., High-Performance Heat Sinking for VLSI, IEEE Electron. Device Letter, EDL-2, vol. 5, pp. 126-129, 1981.

[2] http://www.mie.utoronto.ca/staff/profiles/dli/micheatsink.htm, September 2002.

[3] Obot, N. T., Toward a Better Understanding of Friction and Heat/Mass Transfer in Microchannels-A Literature Review, Microscale Thermophysical Engineering, vol. 6, pp. 155-173, 2002.

[4] Guo, Z. Y., and Li, Z. X., Size Effect on Microscale Single-Phase Flow and Heat Transfer, Proc. 12th Int. Heat Transfer Conf., ed. J. Taine, Elsevier, Grenoble, France, vol. 1, pp. 15-26, 2002.

[5] Sobhan, C. B., and Garimella, S. V., A Comparative Analysis of Studies on Heat Transfer and Fluid Flow in Microchannels, Microscale Thermophysical Engineering, vol. 5, pp. 293-311, 2001.

[6] Wu, P., and Little, W. A., Measurement of Friction Factors for the Flow of Gases in Very Fine Channels Used for Microminiature Joule-Thomson Refrigerators, Cryogenics, vol. 23, pp. 273-277, 1983.

[7] Wu, P., and Little, W. A., Measurement of the Heat Transfer Characteristics of Gas Flow in Fine Channel Heat Exchangers Used for Microminiature Refrigerators, Cryogenics, vol. 24, pp. 415-420, 1984.

[8] Urbanek, W., Zemel, J. N., and Bau, H. H., An Investigation of the Temperature Dependence of Poiseuille Numbers in Microchannel Flow, J. of Micromechanics and Microengineering, vol. 3, pp. 206-208, 1993.

[9] Flockhart, S. M., and Dhariwal, R. S., Experimental and Numerical Investigation into the Flow Characteristics of Channels Etched in $<100>$ silicon, J. of Fluid Engineering, vol. 120, pp. 291-295, 1998.

[10] Qu, W., Mala, M. Gh., and Li, D., Pressure-Driven Water Flows in Trapezoidal Silicon Microchannels, Int. J. of Heat and Mass Transfer, vol. 43, no. 3, pp. 353-364, 2000.
[11] Mala, M. G., Li, D., and Dale, J. D., Heat Transfer and Fluid Flow in Microchannels, Int. J. Heat Mass Transfer, vol. 40, no. 13, pp. 3079-3088, 1997.

[12] Koo, J., and Kleinstreuer, C., Liquid Flow in Microchannels: Experimental Observations and Computational Analyses of Microfluidics Effects, J. of Micromechanics and Microengineering, vol. 13, pp. 568-579, 2003.

[13] Niklas, M., and Favre-Marinet, M., Pressure Losses in a Network of Triangular Microchannels, Proc. First International Conference on Microchannels and Minichannels, ed. S.G. Kandlikar, ASME, Rochester, NY pp. 335-342, 2003.

[14] Hetsroni, G., Mosyak, A., Segal, Z., and Pogrebnyak, E., TwoPhase Flow Patterns in Parallel Micro-Channels, Int. Journal of Multiphase Flow, vol 29, pp. 341-360, 2003.

[15] Yin, J. M., Bullard, C. W., and Hrnjak, P. S., Single-Phase Pressure Drop Measurements in a Microchannel Heat Exchanger, Heat Transfer Engineering, vol 23, pp. 3-12, 2002.

[16] Holman, J. P., Experimental Methods for Engineer, 4th ed., McGraw-Hill, New York, 1984.

[17] Bejan, A., Convection Heat Transfer, 2nd ed., John Wiley \& Sons, New York, 1995.

[18] Gao, P., Le Person, S., and Favre-Marinet, M., Scale Effects on Hydrodynamics and Heat Transfer in Two-Dimensional Mini and Microchannels, Int. J. of Thermal Sciences, vol. 41, pp. 10171027, 2002. 